\title{
Hitit Devleti ile Vassalları Arasında Yapılan Antlaşmalarda Vassallara Getirilen Yükümlülükler
}

\author{
Caner Özdemir \\ Selçuk Üniversitesi Sosyal Bilimler Enstitüsü \\ Eskiçağ Tarihi ABD Yüksek Lisans Öğrencisi \\ canerozdemir1991@gmail.com
}

Öz

MÖ II. binyılda Anadolu'da Kızılırmak Nehri'nin oluşturduğu çekirdek bölge başta olmak üzere bu bölgede yaşamış ve Eski Yakın Doğu'nun en büyük imparatorluklarından birini kurmuş olan Hititler, bu imparatorluğu 450 yıl boyunca ayakta tutmayı başarmışlardır. Hitit Devleti'nin asıl kurucusunun I. Hattušili (MÖ 1650-1620) olduğu kabul edilmektedir. Hattušili, günümüzde Çorum'a bağlı ve $82 \mathrm{~km}$ uzağında bulunan Boğazköy'deki Hattuşa'yı kendine başkent yapmıştır. Hitit idari sistemi genel yapısıyla incelendiğinde iki farklı yapı bulunduğu anlaşılmaktadır. Bunlardan biri vassal statü ile krallığa bağlanmış bölgeler, diğeri ise doğrudan merkeze bağlı olarak yönetilen bölgelerdir. Hitit kralları kendilerine vassal statü ile bağlanmış merkezden uzakta bulunan eyaletleri, kendilerine mutlak sadakat ile bağlı olan güvenilir hanedan üyeleri veya Hitit Kralına yakın bölgenin ileri gelenlerinden birisini vassal kral olarak atayarak yönetirlerdi. Hititlerdeki vassal devlet yapılanmasının I. Šuppiluliuma tarafından oluşturulduğu ve II. Muršili zamanında da geliştiği gözlenmektedir. Yapılan vassal antlaşmalardan 6'şar adeti I. Šuppiluliuma ve II. Muršili tarafından, 3'ü III. Hattušili, 2'şer adeti II. Muwatalli ve IV.Tuthaliya tarafından, diğer 1'er adeti ise II. Tuthaliya ve II. Šuppiluliuma tarafından yapılmıştır. Bu makale, Hitit krallarının vassalları ile yapmış oldukları tüm antlaşmaların içeriğinin incelenerek, bu antlaşmalarla vassallara getirilen benzer ve farklı yükümlülükleri topluca sunmak amacıyla hazırlanmıştır.

Anahtar Kelimeler: Hitit Krallı̆̆ı, vassal antlaşmalar, yükümlülükler.

\section{The Obligations to Vassals in the Treaties between the Hittite State and Their Vassals}

\footnotetext{
Abstract

The Hittites, who lived in the region formed by the Kizılırmak River in Anatolia in the second Millennium BC, established one of the biggest empires of the Ancient Near Eastern and managed to keep this empire alive for 450 years. Hattušili I (1650-1620) is accepted as the founder of the Hittite Kingdom. Hattusa (Boğazköy), which is $82 \mathrm{~km}$ away from Çorum city center today, had been chosen as the capital by Hattušili. When the Hittite administrative system is examined with its general structure, it is understood that there are two different structures: the regions connected to the Kingdom with the vassal status, and 
regions directly connected to the center. The regions connected to the Kingdom with the vassal status were ruled by a vassal king who was appointed by the Hittite King. The vassal king would be one of the trustworthy dynasty members who were wholly loyal to the King, or one of the notables of nearby regions. It is seen that vassal state structure was formed by Šuppiluliuma I and improved by Muršili II. Among the signed 21 vassal treaties, 6 of them were made by Šuppiluliuma I, 6 of them by Muršili II, 3 of them by Hattušili III, 2 each with Muwatalli II and Tuthaliya IV and 1 each with Tuthaliya II and Šuppiluliuma II. This article was prepared to examine the contents of all treaties between vassals and the Hittite kings, and to present similarities and differences of the obligations, given to vassals by these treaties.

Keywords: Hittites Kingdom, Vassal treaties, obligations. 


\section{GíRIŞ}

MÖ II. binyılda Anadolu'da Kızılırmak Nehri'nin oluşturduğu çekirdek bölge başta olmak üzere bu bölgede yaşamış ve Eski Yakın Doğu'nun en büyük imparatorluklarından birini kurmuş olan Hititler, bu imparatorluğu 450 yıl boyunca ayakta tutmayı başarmışlardır. Hititlerin Anadolu'ya geldikleri coğrafya bilim dünyası için tartışma oluşturmakla birlikte, kuzeyden Kafkasya üzerinden deniz yoluyla geldikleri görüşü ağırlık kazanmıştır (Sommer 1947: 3; Macqueen 2015: 27-32; Bahar 2017: 34). Hititlerin Anadolu'ya geldikleri tarihlerde Anadolu'da, yerel beyliklerin hâkimiyeti altında olan küçük şehir devletçikleri bulunduğu belirtilmektedir. Nitekim Kültepe kazılarında çıkarılan tabletlerden edinilen bilgiler de, Asurlu ticaret adamlarının Anadolu'daki bu şehir devletleri ile yoğun ticari ilişkiler içerisinde bulunduklarını ve kullandıkları çivi yazısının da bu yolla Anadolu'ya geldiğini doğrulamaktadır (Özgüç 1986: 1, 14; De Martino 2003: 32-33; Günbattı 2012: 6; Bahar 2013: 203). Ayrıca Hitit öncesi siyasi tarihin aydınlatılması yönünden, yerel beylikler arasında yapılan yazışmalar da önemli olup, bunlardan biri de Mama Kralı AnumHirbi'nin Kaniş Kralı Warşama'ya gönderdiği mektupdur (Balkan 1957: 1; Küçükbezci 2010: 56). Hitit Devleti'nin asıl kurucusunun I. Hattušili (MÖ 1650-1620) olduğu kabul edilmektedir. Hattušili, günümüzde Çorum'a bağlı ve $82 \mathrm{~km}$ uzağında bulunan Boğazköy'deki Hattuşa'yı başkent yapmıştır. Hititlerin devlet yapısı incelendiğinde, her türlü yönetim merkezinin başkent Hattuşa'da bulunan saray olduğu anlaşılmaktadır. Yönetim merkezi olarak kullanılan söz konusu sarayda ise yönetimin başında Tabarna "hükümdar" (Büyük Kral) ile Tawananna olarak adlandırılan kadın hükümdar (Büyük Kraliçe) bulunmakta ve bunları Tuhkanti olarak adlandırılan veliaht izliyordu. Bununla birlikte sarayda devlete ait kayıtların tutulduğu, mektupların ve antlaşmaların hazırlandığı "É.DUB.BA" denilen tablet evi bulunuyordu. Tablet evinde yazışmaları yapanların başında baş yazıcı (GAL DUB:SAR) ile diğer yazıcılar (GAL DUB.SAR.GIŠ) bulunurdu (Alp 2000: 147). Ayrıca krala değişik konularda danışmanlık yapan yaşlılar-soylular meclisi (Pankuš) ve ordunun ileri gelenlerinin oluşturduğu meclis (Dugudlar) idarede rol oynamaktaydı (Bryce 2015: 86).

Hattuşa-Boğazköy'de yapılan kazılarda bulunan sayıları 33.000 üzerindeki çivi yazılı kil tabletlerin transkripsiyon ve tercümeleri Hitit siyasetinin ulaşmış olduğu yüksek seviyeyi göstermesi bakımından önemlidir. Bu tabletlerin bir kısmı devlet antlaşmaları ve mektuplardan oluşan siyasi metinler olmak üzere; kanunlar, kral yıllıkları, bağış belgeleri, dini metinler, mitolojik metinler, dualar ve fal metinlerinden oluşmaktadır. İç hukuk sistemiyle kişilerin ilişkilerini çok dikkatli bir şekilde düzenleyen Hititlerin, dış ülkelerle olan ilişkilerinde de akıllı bir politika yürüttükleri görülmektedir. Buna göre Hititlerin dış politikadaki temel amacı, uluslararası dengelerin kendi lehlerine gelişmesini sağlayarak, düşman ülke sayısını azaltmak olmuştur. Diğer bir ifadeyle Hititler güçlü ülkelerle eşitlik temelinde bir politika yürütürken, küçük ülkeleri ise vassal olarak kendilerine bağlayarak etkisiz hale getirmeye çalışmışlardır (Beckman 1996: 1-2). Bu nedenle Hitit Devlet antlaşmalarını, Hitit krallarının kendileri ile aynı seviyede olan krallar ile yaptıkları eşitlik prensibine dayanan "paritetik" antlaşmalar ve vasalları ile yaptıkları antlaşmalar şeklinde ikiye ayırmak mümkündür. Eşitlik prensibine dayanan antlaşmaya en iyi örnek, III. Hattušili ve II. Ramses arasında yapılan Kadeš antlaşmasıdır (Akdoğan 2010: 96-97).

Bu makale, farklı araştırmacılar tarafından transkripsiyon ve tercümeleri yapılmış Hititlerin vassalları ile yapmış oldukları tüm antlaşmaların içeriğinin ayrıntılı şekilde 
incelenerek, bu antlaşmalarla vassallara getirilen benzer ve farklı yükümlülükleri belirlemek ve bunları topluca sunmak amacıyla hazırlanmıştır.

\section{HITTIT DEVLETİ İLE VASSALLARI ARASINDA YAPILAN ANTLAŞMALAR}

Vassallık, bir devletin tek yanlı olarak diğer devlete mutlak bağımlı olması demektir. Bu bağımlılık kendisini özellikle dış politikada gösterir, yoksa vassal krala kendi iç işlerinde oldukça geniş özgürlük verilmiştir (Ünal 2005: 97). Diğer bir ifadeyle, vassal krallıklar iç işlerinde serbest olmakla birlikte dış işlerinde Hitit kralına bağlıydılar ve yükümlülükleri antlaşmalarda belirtiliyordu (Taş 2012a: 3030; Ayaz 2017: 173). Bu yönetim sistemi sayesinde, bir taraftan dönemin güçlü krallıklarıyla Hitit Devleti arasında bu krallıkların tampon görev yapması sağlanmış, diğer taraftan da merkezden uzakta bulunan bu krallıkların yönetimi kolaylaşmıştır. Hitit kralları bazı durumlarda vassal krala Hitit hanedan soyundan birini eş olarak vererek, bu kral ile Hitit Krallığı arasında güveni artırma politikasını da sıkça kullanmışlardır.

Hitit idari sistemi genel yapısıyla incelendiğinde iki farklı yapı bulunduğu anlaşılmaktadır. Bunlardan biri daha önce ifade edildiği gibi vassal statü ile krallığa bağlanmış bölgeler, diğeri ise doğrudan merkeze bağlı olarak yönetilen bölgelerdir. Merkeze bağlı bölgeler Kızılırmak kaynak bölgesi ve yukarı kısımlarını içeren, Hitit merkezinin doğu ve kuzeydoğusunu içeren Yukarı Ülke (KUR UGU ${ }^{T 1}$ ) ile Kızılırmak'ın Orta Anadolu'da çizdiği geniş kavis bölgesinin güneyini içeren Aşağı Ülke (KUR ŠAPLITI) kısmıdır (MonteTischler 1978: 293-294; Yiğit 2004: 220). Hitit kralları kendilerine vassal statü ile bağlanmış merkezden uzakta bulunan eyaletleri, kendilerine mutlak sadakatla bağlanacak olan güvenilir hanedan üyeleri veya Hitit Kralına yakın bölgenin ileri gelenlerinden birisini vassal kral olarak atayarak yönetirlerdi (Ünal 2005: 100). Hititlerdeki bu devlet yapılanmasının I. Šuppiluliuma tarafından oluşturulduğu ve II. Muršili zamanında da geliştiği gözlenmektedir. Özellikle I. Šuppiluliuma'nın Suriye'nin kuzey bölgesine yaptığ seferlerden sonra, ele geçirilen yeni bölgelerin merkezden idaresi zor olacağı için bu vassal krallık sistemi uygulanmaya başlanmıştır (Sir Gavaz 2008: 35).

Hitit Krallığı döneminde gerek Anadolu sınırları içerisinde gerekse Mezopotamya bölgesinde fazla sayıda vassal krallık ve eyalet yöneticileri bulunmaktaydı. Bu kapsamda Anadolu toprakları üzerinde Hurri-Mitanni Krallığı, Kizzuwatna Krallığı, Išuva Ülkesi, Azzi-Hayaša Ülkesi ve Arzawa Ülkeleri (Šeha Nehri Ülkesi, Hapalla, Wiluša, MiraKuwaliya) krallıkları ile Anadolu sınırları dışında ise Kargamıš, Halep, Ugarit, Amurru, Nuhašše ve Kinza memleketleri dönem dönem vassal statüyle Hititlere bağlıydılar (Alemdar 2006: 15-16). Bugün ele geçen ve transkripsiyonları yapılan Hitit siyasi metinlerinin çoğunu da, yukarıda adı geçen bu krallıklarla yapılan antlaşma metinleri oluşturmaktadır.

Yapılan vassal antlaşmaların içeriği küçük istisnalar dışında, genelde belirli bir düzen içerisinde ve devlet dili kullanılarak yazılmıştır. Antlaşma metinleri Büyük Kralın başkanlığındaki bir ekip tarafından hazırlanıp, vassal krala sunulurdu. Bu metinler saraydaki yazıcılar tarafından bazen gümüşten ancak genelde bronz veya demir tabletler üzerine çivi yazısı ile yazılmıştır. Antlaşma metinlerinde öğelerin sıralanışında bazı istisnalar olsa da büyük bir bölümü antlaşmayı hazırlayan Hitit kralının ismi, ünvanı, lakabı, babasının ismi bazen de soy ağacının yazıldığı önsöz ile başlamaktadır (ChristiansenDevecchi 2013: 69-71). Yapılan antlaşmaların önsöz bölümünü genellikle tarihi geçmiş izler ve bu bölümde antlaşma yapılan vassal, ona verilen ülke ile Hitit kralı veya Hatti Ülkesi 
arasındaki ilişkiler hakkında bilgi verilirdi. Daha sonraki bölümde ise antlaşma şartlarını oluşturan Hitit kralına sadakat, sınırlar, askeri yükümlülükler, vergiler, ayaklanma ve dış düşmanlara karşı savunma, esirlerin durumu, yalan söylemler ve tabletin yıllık okunmasına ilişkin şartlar belirtilmiştir. Antlaşma metinlerinin son bölümündeyse, söz konusu antlaşma metninin, vassal krallığın baş tanrısına ait tapınağa yerleştirilerek belirli aralıklarla okunmasına ilişkin kurallar ile yemin tanrıları, tanıkların listesi, beddua ve lütuf bölümü yer almaktadır (Beckman 1996: 2-4; Akdoğan 2010: 98-102). Metinlerde geçen lanet ve lütuf sözleri yalnızca vassal krala yönelik olup, bu kral antlaşmayı bozduğunda tanrılar kralı ve ailesini tamamen mahvedecek, antlaşmaya uyduğu sürece ise tanrılardan ve Hitit Kralı'ndan sürekli iyilik görecektir şeklinde ifadelere yer verilirdi (Akdoğan 2010: 102).

Hitit Devleti ile vassalları arasında yapılmış birçok antlaşma metnine ulaşılmış olup, bu antlaşmalar aşağıda verilmiştir:

Kizzuwatna ülkesiyle yapılan antlaşmalar: MÖ II. binyılda Anadolu'nun güneyinde yer alan ve antik dönemde Kilikya olarak adlandırılan Kizzuwatna Ülkesi, coğrafi olarak Kuzey Suriye'ye açılan kapı konumunda yer almakta ve Hurri kültürünü barındırmaktaydı (Goetze 1962: 48; Monte- Tischler 1978: 211-216; Ünal 2006: 18, Pelvanoğlu 2017: 1). Kizzuwatna Ülkesi'yle vassal statüde yapılmış iki antlaşma bulunmakta olup bunlar, a) Kizzuwatna'lı Šunaššura ile Hitit Kralı II.Tuthaliya arasında, b) I. Šuppiluliuma ile oğlu Telipinu, diğer oğlu prens Arnuwanda, Büyük Kraliçe Henti ve saray muhafızlarının şefi Zida arasında yapılmıştır (Beckman 1996: 13; Alemdar 2006: 88, 175; Kitchen- Lawrence 2012: 315-320).

Arzawa ülkeleriyle yapılan antlaşmalar: Arzawa Ülkeleri ya da birliği (Šeha Nehri Ülkesi Krallığı, Hapalla Krallığı, Mira-Kuwaliya Krallığı, Wiluşa Krallığı) olarak bilinen bu ülkeler arasındaki işbirliği II. Muršili tarafından dağıtılarak, kendileriyle dört antlaşma yapılmıştır. Bu antlaşmalar, a) Hapalla Kralı Targašnalli ile II. Muršili arasında, b) Mira Kuwaliya Kralı Kupanta-Kurunta ve II. Muršili arasında, c) Šeha Nehri Ülkesi Kralı ManapaTarhunta ile II. Muršili arasında, d) Wiluša Kralı Alakšanduš ile II. Muwattali arasındaki antlaşmadır (Beckman 1996: 64, 69, 77, 82; Karauğuz 2002: 113, 119, 132, 139).

Amurru ülkesiyle yapılan antlaşmalar: Coğrafik olarak bugün ki Lübnan'ın sahil kesimine lokalize edilen Amurru, Hitit ve Mısır Krallığı'nın egemenlik bölgeleri arasında tampon bir krallıktı. Hitit Krallığı'nın Amurru Krallığı ile yaptığı dört antlaşma metni bulunmakta olup, bu antlaşmalar; a) Aziru ve I. Šuppiluliuma arasında, b) Tuppi-Tešup ve II. Muršili arasında, c) Bentešina ve III. Hattušili arasında, d) Šaušga-muwa ve IV. Tuthaliya arasında yapılmıştır (Beckman 1996: 32, 54, 95, 98; Alp 2000: 143; Taş 2008: 202).

Azzi-Hayaša ülkesiyle yapılan antlaşma: Coğrafik olarak Anadolu'nun kuzey doğusuna lokalize edilen bu ülkeye (Demirel 2017: 98), I. Šuppiluliuma tarafından vassal kral olarak atanan Huqqana ile bir antlaşma yapılmıştır (Beckman 1996: 22; Alp 2000: 99).

Ugarit ülkesiyle yapılan antlaşmalar: Ugarit Krallığı, günümüzde Lazkiye'nin güneyinde yer alan bir ülkeydi (Sir Gavaz 2012: 26). Anadolu ve Mısır arasındaki ulaşımı sağlayan yolda, zengin bir ticaret şehri olan Ugarit'ten geçmekteydi. Ugarit, Hitit Kralı I. Šuppiluliuma'nın yardımıyla düşmanlarının yenilmesinden sonra yapılan antlaşma ile Hititlerin vassal krallığ1 haline gelmiştir (Alp 2000: 90). Hitit Krallığ1 ile Ugarit Ülkesi arasında yapılmış iki antlaşma metni bulunmakta olup, bunlar; a) II. Nigmaddu ve I.

SEFAD, 2018 (40): 267-282 
Šuppiluliuma arasında; b) Niqmepa ve II. Muršili arasında yapılmıştır (Beckman 1996: 30, $59)$.

Mitanni ülkesiyle yapılan antlaşma: Coğrafik olarak Suriye'nin kuzey bölgesinde Kerkük'ten Akdeniz'e kadar uzanan bölgede yer alan ve halkının çoğu Hurri kökenli olan Mitanni (Alpman, 1981: 303), Asur ile Hitit Krallı̆̆ı'nın sınırları arasında tampon bir görev yapmaktaydı. Hitit Kralı I. Šuppiluliuma kızını da eş olarak kendisine verdiği Mattiwaza'yı, bu ülkeye vassal kral yaparak bir antlaşma yapmıştır (Beckman 1996: 38; Alp 2000: 93).

Nuhašše ülkesiyle yapılan antlaşma: Halep'in güneyinde yer alan ve başlangıçta Mitanni yönetiminde bulunan Nuhašše ülkesi (Bryce 2003: 133), I. Šuppiluliuma tarafından işgal edilerek vassal kral olarak atanan Tette ile bir antlaşma yapılmıştır (Beckman 1996: 50).

Tarhuntašša ülkesiyle yapılan antlaşmalar: II. Muwatalli döneminde Hititlerin idari merkezi olan bu ülke, daha sonraki yıllarda bu statüsünü kaybetmiş ve vassal krallık haline gelmiştir (Ayaz 2017:177). Bu ülke ile yapılmış 3 adet antlaşma metni bulunmuş olup bunlar; a) Kurunta'nın askeri yükümlülükleri hakkında III. Hattušili'nin emirlerini içeren metin, b) Ulmi-Tešup ve III. Hattušili arasındaki antlaşma, c) Kurunta ve IV. Tuthaliya arasındaki antlaşmadır (Otten 1988: 3; Bahar-Karauğuz vd. 1996: 46-50; Beckman 1996: 103, 104, 108).

Kargamıš ülkesiyle yapılan antlaşmalar: Kargamıš Krallığı, Fırat Nehri ile Akdeniz arasında kalan Kuzey Suriye bölgesinde hakimiyetini sürdürmüştür (Taş 2012a: 3031; Bryce 2003: 131). Hitit Krallığı ile Kargamıš Ülkesi arasında iki antlaşma metni bulunmakta olup, bu antlaşmalar; a) Piyaššili ve II. Muršili arasında, b) Talmi-Tešup ve II. Šuppiluliuma arasındaki antlaşmadır (Beckman 1996: 154; D' Alfanso 2007: 211).

Halep ülkesiyle yapılan antlaşma: Halep, Suriye'nin kuzeyinde önemli ticaret yolları üzerinde bulunan ve küçük krallıklardan oluşan Yamhad Konfederasyonunun başkenti olması nedeniyle, Halep Krallığı olarak da anılmaktaydı ( Bryce 2003: 132; Peker 2013: 65). Hitit Krallığı ile Halep Ülkesi arasında yapılmış bir antlaşma bulunmakta olup, antlaşma Talmi-Šarruma ve II. Muwattalli arasında yapılmıştır (Karauğuz 2002: 228).

\section{VASSAL ANTLAŞMALARDA VASSAL KRALLARA GETIRILEN YÜKÜMLÜLÜKLER}

Hitit krallarının vassal krallarla yapmış oldukları antlaşmaların içerikleri incelendiğinde, Hititler'in Anadolu'da uzun yıllar egemenliklerini sürdürdüklerinin nedenleri kolayca anlaşılacaktır. Nitekim Hitit kralları yaptıkları bu antlaşmalarda, öncelikle antlaşma yaptıkları tarihlerde uluslararası güç dengelerini daima göz önünde tutmuşlardır. Ayrıca antlaşma yaptıkları krallığın başta ekonomik ve askeri gücü olmak üzere, coğrafi konumlarının da antlaşma metinlerinin içeriği üzerinde etkili olduğu düşünülmektedir. Hitit kralları, Hatti topraklarının güvenliğini sağlamak amacıyla, Asur ve Mısır gibi dönemin güçlü ülkeleri ile kendi sınırları arasında tampon ülke oluşturmak amacıyla, bu konumdaki ülkelere güvenilir vassal kral atayarak yönetmişlerdir. Ayrıca dönemin önemli ticaret yolları üzerinde bulunan krallıklarla da ilgilenerek, uluslararası ticarette Hattili tüccarların etkin olmasını sağlamışlar, bazı durumlarda da bu avantajlarını düşman ülkelere ambargo uygulayarak üstünlüklerini korumuşlardır (Taş 2012b: 3015). Hitit hanedan soyundan olan krallar tarafından yönetilen (Kargamıš, Halep ve Tarhuntašša krallıkları) ülkelerin dışındaki vassal kralların, atandıkları dönemin siyasi koşulları göz önüne alındığında bunlardan bazılarının ülkelerinin Hitit Krallığı'nın saldırısı sonrasında, 
bazılarının başka bir ülkenin tehdidi karşısında Hitit Krallı̆̆ı'ndan yardım talepleri sonrasında veya kendilerinin Hitit buyruğunu kabul etmelerini takiben atandıkları anlaşılmaktadır. Buna ek olarak bazı ülke krallarının (Ugarit Kralı Niqmepa, Azzi-Hayaşa Kralı Huqqana) Hitit Krallığg'na ihanet etmiş olmasına karşın, yine de kendilerinin veya oğullarının vassal kral olarak atandığ1 görülmektedir. Bu krallarla yapılan antlaşmalarda, vassal kralı aşağılayııı cümlelerin kullanılmış olması dikkat çekici olup, bununla vassal krala gözdağı verildiği düşünülmektedir. Dolayısıyla bu krallarla yapılan antlaşmalarda, bu kralların mevcut statüsünün muhtemelen antlaşma metinlerine yansıdığı söylenebilir.

Nitekim bu duruma Ugarit Kralı Niqmepa ile II. Muršili arasında yapılan antlaşmanın ilk bölümünde rastlanmakta ve bu bölümde II. Muršili Niqmepa'ya "seni babanın tahtına ben yerleştirdim" ifadesini kullanmıştır (Beckman 1996: 60). Benzer şekilde Azzi-Hayaşa Kralı Huqqana ile I. Šuppiluliuma arasında yapılan vassal antlaşmada ise I. Šuppiluliuma Huqqana'ya "alçak köpek- a lowly dog" diye hitap etmektedir (Beckman 1996: 23). Diğer taraftan Hitit krallarının evlikler yoluyla ilişki kurdukları vassallarıyla yaptıkları antlaşmalarda, bu özel durumu göz ardı etmedikleri görülmektedir. Nitekim II. Muršili tarafından Mira-Kuwaliya Krallığı'na atanan Kupanta-Kurunta (Babası II. Muršili'nin kız kardeşiyle evlenmiştir) ile II. Muršili arasında akrabalık ilişkisi mevcut olup, yapılan antlaşmada II. Muršili Kupanta-Kurunta'nın diğer Arzawa Ülkeleri kralları (ManapaTarhunta, Targašnalli) tarafından korunmasını ve bu krallarla müttefik olmalarını yemin altına almıştır (Karauğuz 2002:129). Özellikle doğrudan Hitit hanedan üyesi kralları tarafından yönetilen Tarhuntaşşa Krallığı, Kargamış Krallığı ve Halep Krallığı Ülkesi'nin vassal kralları ile yapılan antlaşmalarda getirilen yükümlülüklerin, diğer vassal krallara getirilen yükümlülüklerden farklı olduğu kolayca anlaşılmaktadır. Nitekim bazı araştırmacılar (Christiansen- Devecchi 2013: 70) bu antlaşmaların sözde ve yarı eşitlik koşullarında yapılmış olduklarını ileri sürmektedir. Hitit krallarının hanedan üyesi vassal krallarla yaptıkları antlaşmalarda, zekice bir politika izledikleri anlaşılmaktadır. Çünkü bu antlaşmalarda, hanedan üyesi vassal kralların gelecekte Hitit tahtına yönelik hak iddia etmeyecekleri açıkça belirtilmiş ve belki bu nedenle de kendilerine ayrıcaklı ödünler verilmiştir.

Nitekim Tarhuntaşşa Kralı Kurunta ile IV. Tuthaliya arasında yapılan antlaşmada Kurunta'nın askeri yükümlülüklerinin hafifletilmesi ayrıca Šahhan ve Luzzi vergilerinden muaf tutulması bunun en iyi kanıtlarındandır (Beckman 1996: 114-115).

\section{VASSAL KRALLARA GETİRILEN ORTAK YÜKÜMLÜLÜKLER}

Hitit krallarının vassal krallarla yaptıkları antlaşmaların içeriği incelendiğinde, bu antlaşmaların çoğunda geçen ve yemin altına alınmış benzer yükümlülüklerin bulunduğu görülmektedir. Hitit Devleti'nin ekonomisi açısından vassal krallıklardan alınan vergilerin önemli bir payı bulunduğundan, bu antlaşmalarda vassal kralların vereceği yıllık vergiler yemin altına alınmıştır. Diğer taraftan tam sadakatle Büyük Krala bağlılığı istenen vassal krallar da, bu bağlılığın göstergesi olarak, Büyük Kralın dostuyla dost, düşmanıyla düşman olmaları tüm bu antlaşmalarda bulunmaktadır. Aynı şekilde bu antlaşmalarda savaş ve isyan durumlarında bu kralların hemen yaya ve arabalı savaşçılarıyla Büyük Kralın yardımına gitmesi ve sınırlarının korunması gibi konular yemin altına alınmıştır. Yine bu antlaşmaların çoğunda vassal krallar ortak yükümlülük olarak kaçaklar, kışkırtıcılar, yalan haber yayanlar, suçlular, isyancıların durumu ve haklarında yapılacak işlemler detaylı olarak açıklanarak yemin altına alınmıştır. Ayrıca bu antlaşmaların tümünde bu krallara 
Büyük Kral ile ailesine ve gelecekteki tüm nesline itaat etmesi ve onları korumasına yönelik yükümlülük getirilmiştir.

\section{VASSAL KRALLARA GETIRILLEN FARKLI YÜKÜMLÜLÜKLER}

Hitit Devleti'nin vassal krallıklarla yaptığı antlaşmaların içeriği incelendiğinde, bu antlaşmalarla bu krallara getirilen bazı yükümlülüklerin farklı olduğu görülmektedir. Bu farklılıklar muhtemelen antlaşma yapılan vasal krallığın jeopolitik konumu ile siyasi koşullardan ileri gelmiş olmalıdır. Çünkü bu krallardan bazıları ülkeleri Hitit Krallığı tarafından ele geçirildikten sonra, bazıları diğer güçlü ülkelerin tehdit etmeleri nedeniyle Hitit Krallığı'ndan yardım istemeleri neticesinde veya doğrudan Hitit buyruğuna girmek istedikleri için atanmışlardır. Doğal olarak yukarıda belirtilen farklı üç koşulda da yapılan antlaşmalarda, kozlar Hitit Devleti'nde olması nedeniyle antlaşmalarda Hitit çıkarlarını koruyan farklı yükümlülükler getirilmiştir. Yine vassal krallıklarla yapılan antlaşmaların içeriğinden, Šeha Nehri Ülkesi Kralı Manapa-Tarhunta ve Amurru Kralı Benteşina gibi bazı kralların Hitit Devleti'ne ihanet etmesine rağmen, Büyük Kral tarafından bağışlanarak kral olarak atandığı görülmekte olup (Beckman 1996: 78; Karauğuz 2002: 193), bu vassal krallarla yapılan antlaşmalarda da bazı özel yükümlülükler getirilmiştir.

Kizzuwatna ülkesiyle yapılan antlaşmalarda getirilen farklı yükümlülükler: Hitit Devleti'nin Kizzuwatna Ülkesiyle yaptığı antlaşma Šunaššura ile Hitit Kralı II. Tuthaliya arasında yapılmıştır. Muhtemeldir ki bu antlaşma Kizzuwatna'nın bağımsızlığını yitirdiği dönemde yapılmıştır. Çünkü bu antlaşmanın giriş bölümünde Hitit Kralı şimdi Kizzuwatna Ülkesi ve halkı Hitit sığırıdır "i-na-an-na KUR URU Ki-iz-zu-ua-at-ni ša URU Ha-at-ti GU ${ }_{4}$HIIA$^{\prime}$ ", diyerek sığırlar ahırını seçti "É GU HI.A.šu-nu ŭ-wa-ad-du-nim-mi ap-pu-na-am-ma" ifadesini kullanmıştır (Alemdar 2006: 98-99). Ancak bu antlaşmada diğer vassal antlaşmalardan farklı olarak Šunaššura vergiden muaf tutularak, Büyük Kralı ziyareti sırasında kralın adamları tarafından ayakta karşılanacağı, kendisine iyi davranılacağı ve ülkesine istediği zamanda dönebilmesi konusunda ayrıcalıklar verilmiştir. Fakat bu antlaşmayla Šunaššura'ya Hurri Ülkesi'ne elçi göndermemesi ve Hurri elçisini kabul etmemesi konusunda yükümlülük getirilmiştir (Alemdar 2006: 101, 131; Kitchen-Lawrence, 2012: 315-320). Ayrıca Mitanni Devleti Hatti topraklarına saldırırsa, Šunaššura'nın Mitanni askerlerinin kendi topraklarından geçişine izin vermemesi konusu antlaşmada yemin altına alınmıştır. Diğer taraftan Hitit Devletinin, Hurri ve Arzawa Ülkeleri'yle yaptığı bir savaş durumunda, Šunaššura Hitit Devletine yüz süvari ve bin atlı asker vermekle yükümlülük altına alınmıştır (Alemdar 2006: 131; Kitchen-Lawrence, 2012: 315-320). I. Šuppiluliuma ile oğlu Telipinu, diğer oğlu prens Arnuwanda, Büyük Kraliçe Henti ve saray muhafızlarının şefi Zida arasında yapılan antlaşmada ise Telipinu prens Arnuwanda'nın gelecekte Hitit Krallığ üzerindeki hakkını kabul etmekle yükümlü tutulmuştur (Alemdar 2006: 176, 178).

Arzawa ülkesiyle yapılan antlaşmalarda getirilen farklı yükümlülükler: Arzawa Ülkeleri'nden Šeha Nehri Ülkesi Kralı Manapa-Tarhunta ile II. Muršili arasında yapılan antlaşmada ise diğer antlaşmalardan farklı olarak Manapa-Tarhunta, II. Muršili tarafından güven duymadığı Mira-Kuwaliya Kralı Mašhuiluwa konusunda uyarılmıştır. Ayrıca bu antlaşmada Manapa-Tarhunta ile Mašhuiluwa'nın birbirlerine karşı kötülük, düşmanlık beslememeleri ve birbirlerinin düşmanlarıyla işbirliği yapmamaları konuları yemin altına alınmıştır. Yine bu antlaşma ile Manapa-Tarhunta, Arzawa Ülkesi'nden kendisine gelecek tüm kaçakları (NAM.RA) yakalayarak, II. Muršili'ye teslim etmekle yükümlü kılınmıştır (Beckman 1996: 78; Karauğuz 2002: 134). Yine Arzawa Ülkesi olan Hapalla Kralı Targašnalli 
ile II. Muršili arasında yapılan antlaşmada ise II. Muršili saray içinden veya dışından kendisine karşı yapılacak bir isyan sonucunda, Targašnalli'ye sığınacak kaçakların hemen kendisine teslim edilmesi ve Targašnalli'nin garnizonunda bıraktığı Hitit askerlerine iyi bakması yemin altına alınmıştır. Yine bu antlaşmayla Targašnalli'ye şayet kulağına II. Muršili'nin kendisi hakkında kötü düşündüğüne dair dedikodu haber ulaşırsa, bunu hemen kendisine yazması ve cevap gelmeden kendisine karşı kötülük yapmaması konusunda yükümlülükler getirilmiştir (Beckman 1996: 65-66; Karauğuz 2002:114). Diğer bir Arzawa Ülkesi olan Mira-Kuwaliya Kralı Kupanta-Kurunta ile II. Muršili arasında yapılan antlaşmada ise diğer antlaşmalardan farklı olarak, bu antlaşmada Kupanta-Kurunta'nın II. Muršili'nin yeğeni olmasından dolayı olacak ki, diğer Arzawa Ülkesi krallarının kendisini koruması ve Kupanta-Kurunta'nın antlaşma metnini yılda üç kez okuması yemin altına alınmıştır (Beckman 1996: 76). Wiluşa Kralı Alakšanduš ile II. Muwatalli arasında yapılan antlaşmada ise vassal kral antlaşma metnini yılda üç kez okumak, Kupanta-Kurunta'nın korunması ve Šeha Nehri Ülkesi kaynaklı isyan durumunu hemen Büyük Krala bildirmekle ayrıca şayet Büyük Kral duymasa da, Alakšanduš ona karşı bir isyanı duyduğunda hemen yaya ve arabalı savaşçılarıyla harekete geçmekle ve işi kuş falı bakmaya bırakmamakla yükümlü tutulmuştur (Beckman 1996: 84).

Mitanni ülkesiyle yapılan antlaşmalarda getirilen farklı yükümlülükler: I. Şuppiluliuma'nın kızıyla evli olan Mitanni Kralı Mattiwaza ile I. Šuppiluliuma arasında yapılan antlaşmada Mattiwaza, Büyük Kralın oğulları ile eşit statüde ve kardeş olarak kabul edilerek, kendisine Hattide birde ev verilmiştir. Ancak Mattiwaza I. Šuppiluliuma tarafından başkasıyla da evlenme konusunda serbest bırakılmakla birlikte, eşi I. Şuppiluliuma'nın kızının kraliçe olacağı ve her zaman diğer eşlerinden üstün olacağ sözleriyle yükümlülük altına alınmıştır (Beckman 1996: 40-41). Ayrıca Mattiwaza'nın Kargamış Kralı Piyaššili ile dostça geçinmesine ilişkin sözler de yemin altına alınmıştır.

Ugarit ülkesiyle yapılan antlaşmalarda getirilen farklı yükümlülükler: Ugarit Krallığı ile yapılan vassal antlaşmalardan II. Niqmaddu ile I. Šuppiluliuma arasında yapılan antlaşmada, diğer antlaşmalardan farklı olarak II. Niqmaddu antlaşma tabletindeki sözleri değiştirmemekle yükümlü tutulurken, diğer taraftan da ödeyeceği haracın detayları (Efendim Majestem Büyük Krala 12 Mana 20 şekel altın, 1 Mana ağırlığında bir altın kupa başlıca haraç olup, ayrıca 4 keten giysi, 500 şekel mavi erguvan yün, 500 şekel kırmızı ergüvan yün v.b) belirtilmiştir (Alp 2000: 91). Diğer bir Ugarit Kralı Niqmepa ise II. Muršili tarafından sadece Büyük Hitit Kralını korumak, Mısır ya da Hanilgabat kralını korumamakla yükümlü tutulmuştur (Karauğuz 2002: 173).

Nuhašši Krallığı ile yapılan antlaşmalarda getirilen farklı yükümlülükler: Nuhašši Krallığı ile yapılan antlaşmada ise I. Šuppiluliuma Nuhašši Kralı Tette'yi, Hattili tüccarların tartı sistemine göre tartılacak --- şeqel altını yıllık vergi olarak vermekle yükümlü tutmuştur. Ayrıca bu antlaşma tabletinin içerisinde yer alan Tette'nin yılda bir kez Büyük Kralı ziyaret etmesine ilişkin sözleri ile Hitit Devleti'nin Hurri, Mısır, Babil, Aştata ve Alşi ile girebileceği bir savaşta Tette'nin tüm yaya ve arabalı savaşçlarıla hemen yardıma gitmesi sözleri yemin altına alınmıştır (Beckman 1996: 51).

Azzi-Hayaša ülkesiyle yapılan antlaşmalarda getirilen farklı yükümlülükkler: Diğer antlaşma tabletlerinden farklı olarak, I. Šuppiluliuma kız kardeşini verdiği Azzi-Hayaşa Ülkesi Kralı Huqqana ile yaptığı antlaşmada, Azzi-Hayaşa geleneklerine göre normal görülen kız kardeş, eşin kız kardeşi ve kuzen ile cinselliğin Hatti ülkesinde yasak ve 
cezasının ölüm olduğu belirtilmiş ve sarayın özgür kadınları ile cariyeleri konusunda Huqqana uyarılarak bu sözleri yemin altına alınmıştır (Beckman 1996: 27-28; Alp 2000: 99).

Amurru ülkesiyle yapılan antlaşmalarda getirilen farklı yükümlülükler: Kendi isteği ile Hitit köleliğini kabul eden Amurru Kralı Aziru ile I. Šuppiluliuma arasında yapılan antlaşmada, diğer antlaşmalardan farklı olarak Aziru'nun yıllık vergi olarak Hattili tüccarların tartı sistemine göre tartılmış birinci sınıf kalitede işlenmiş 300 seqel altını vermesi, yılda bir kez Büyük Kralı ziyaret etmesi ve Amurru'ya gönderilecek Hattili askerlere bakma görevi yemin altına alınmıştır (Beckman 1996: 33, 35). II. Muršili döneminde Amurru vassal kralı olan Tuppi-Tešup ile yapılan antlaşmada ise yukarıda belirtilen yıllık vergi ve Hattili askerlerin bakımına ilave olarak, Tuppi-Tešup Mısır ülkesine vergi ödememekle yükümlü tutulmuştur (Beckman 1996: 56). Hitit Devletine ihanet etmesine rağmen, III. Hattušili tarafından bağışlanıp (III. Hattušili'nin kızı Gassuliiawiia'da kendisine eş olarak verilen) Amurru vassal kralı olan Benteşina ile yapılan antlaşma tabletinin içeriği Azuri ile yapılan antlaşmanın benzeri olmakla birlikte, bu antlaşmada ki farklılık sadece Büyük Kraliçe olarak III. Hattuşili'nin eşi Phuduhepa'nın isminin geçmiş olmasıdır. Daha sonraki yıllarda Amurru'ya IV. Tuthaliya tarafından vassal kral yapılan Şauşga-muwa ise IV. Tuthaliya'nın kız kardeşi ile evli olup, kendisiyle yapılan antlaşmada diğer antlaşmalardan farklı olarak, Amurru'lu tüccarların Asur ülkesine gitmemesi, Asurlu tüccarların Amurru'ya girişine izin verilmemesi, şayet girerlerse yakalanarak Büyük Krala teslim etmesi, ayrıca Ahiiawa ülkesine ait gemilerin Asur'a gitmesinin engellenmesi ve Asur ile yapılacak savaş için arabalı ordu kurması konularında yükümlü tutulmuştur (Beckman 1996: 101; Alp 2000: 145).

Kargamıš ülkesiyle yapılan antlaşmalarda getirilen farklı yükümlülükler: Hitit hanedan üyeleri tarafından yönetilen vassal krallıklarla (Kargamıš, Halep ve Tarhuntašša krallıkları) yapılan antlaşmalardan birisi olan II. Muršili ile kardeşi Kargamıš Kralı Piyaššili arasındaki antlaşmada, Piyaššili ve gelecekteki soyunun sürekli Kargamı̌̌ vassal kralı olacakları ve Kargamıš Kralının statüsünün ise Hatti Büyük Kralından sonra geleceği yemin altına alınmıştır (Beckman 1996: 154). Daha sonraki Kargamıš Kralı Talmi-Tešup ile II. Şuppiluliuma arasındaki antlaşmada ise II. Šuppiluliuma'nın her zaman vassal kralın yanında olacağı ve gelecekte oğullarının kral olarak göreve devam edeceğinin sözü verilmiştir.

Halep ülkesiyle yapılan antlaşmalarda getirilen farklı yükümlülükler: Halep Ülkesi Kralı Talmi-Šarruma ile II. Muwatalli arasında yapılan antlaşmada ise iki ülkenin krallarının ve nesillerinin karşılıklı birbirlerini koruması ile gelecekte "Halep Ülkesi Krallığı Hatti Ülkesi Kralliğı'ndan üstün olmasın" ifadeleri yemin altına alınmıştır. Ayrıca bu antlaşmada, hanedan üyesi olmayan vassal krallıklarla yapılan antlaşmalarda geçmeyen tabletin kimlerin huzurunda ve kim tarafından yazıldığı da belirtilmiştir. Bu antlaşmanın son bölümünde buna ilişkin olarak "kral ailesindeki subayların şefi [-] libbi, Kargamış Ülkesi Kralı Šahuruwa, rahiplerin şefi Gaššu, Du-[ ]li uriianni, katiplerin şefi Mittana-muva, kralın antuwašalli'si, ve katibi LAMA-piia huzurunda, Hattuša'da katip [ ] bu tableti yazdı" ifadeleri tablette yer almıştır (Karauğuz 2002: 231).

Tarhuntašša ülkesiyle yapılan antlaşmalarda getirilen farklı yükümlülükler: Tarhuntašša Kralı Ulmi-Tešup ile III. Hattušili arasında yapılan antlaşmada, "gelecekte Tarhuntašša Ülkesi krallı̆̆ı sadece Ulmi-Tešup'un soyuna ait olsun" sözlerine yer verilmiş olup, ailede erkek çocuk olmasa dahi kız çocukların vassal kral olabileceği belirtilmiştir (Beckman 
1996: 104; Karauğuz 2002: 86). Ayrıca gelecekte Hitit Krallarının Tarhuntašša Ülkesi'ni UlmiTešup'un soyundan almayacakları ve bunun için mahkemeye gitmeyecekleri antlaşma tabletinde yer almıştır. Bu antlaşmayla Ulmi-Tešup Šuhhan ve Luzzi vergileri ile tablet evi için vermesi gereken askerlerden muaf tutulurken, diğer taraftan şu sözler "Ĕ̆ger onunla eş durumdaki bazı krallar, Majestesine karşı gelirse, Tarhuntašša ülkesi kralı bizzat kendi yardıma gelsin. Fakat ondan yaya ve arabah savaşçlar istemesinler" antlaşmada yer almıştır (Beckman 1996:106; Karauğuz 2002: 89). Yine bu antlaşma tabletinde diğer antlaşmalarda bulunmayan şu ifadeler "Ĕ̆ger Majestem, Ulmi-Tešup'tan bir şehir ya da herhangi bir yer isterse, o memnuniyetle ona bu yerleri versin. Baskı için bir mesele olmasın. Ya da eğer Ulmi-Tešup, Majestemden bazı şeyler isterse, Majestem ona, onu versin" yer almış olup, ayrıca Ulmi-Tešup antlaşma tabletinin sözlerini değiştirmemekle yükümlü k1lınmıştır. Bu antlaşmanın son bölümünde antlaşmanın "tuhkanti Nerikkaili, tuhkanti Tašmi-Šarruma, prens Hannuttti, prens Huzziia, Kargamı̌ ülkesi kralı İni-Tešup, İsuwa ülkesi kralı Ari-Šarruma, Uriianni'li AMAR.MUŠEN, general HattušaKurunta, katiplerin şefi UR.MAH-ziti " ve diğer sıralanan isimlerin huzurunda Urikina şehrinde yazıldığı belirtilmiştir (Beckman 1996: 108; Karauğuz 2002: 92).

Yine III. Hattušili'nin Tarhuntašša vassal kralı Kurunta'nın askeri yükümlülüklerine ilişkin buyruğunda, III. Hattušili yeğeni Kurunta'yı Tarhuntašša Ülkesi'nde kral yaptığını belirterek, diğer antlaşmalardan farklı olarak şu sözleri "Hatti Ülkesi'nin Majestesi talebi olan, tablet evi için Hulaia ülkesi yaya ve arabalı savaşçllarını muaf tuttu, gelecekte sadece 200 asker Hitit askeri seferine gitsin, ayrica tablet evi için ondan asker istenmesin. Bu askerler Šahhan ve Luzzi vergileri olarak ondan kaldırıldı. Büyük Krala karşı onunla eş krallardan biri ayaklanırsa, bizzat kendi yardıma gelsin, fakat kesinlikle ondan bir ordu istenmesin" yemin altına alınmıştır (Beckman 1996: 103; Karauğuz 2002: 83-84). Kurunta ile IV. Tuthaliya arasında yapılan antlaşmada ise III. Hattušili zamanında Kurunta'ya konan Türbe ziyareti yasağı kaldırılarak, Tarhuntašša Ülkesi tanrılarının ihtiyaçlarının Hitit Krallığı tarafından karşılanacağı ve bunun için Hattuşalı insanların, her yıl iki yüz sığır ve bin koyunu Tarhuntašša tanrılarına bağış yapacakları belirtilmiştir (Karauğuz 2002: 97-98). Yine bu antlaşma ile Kurunta Šahhan ve Luzzi vergilerinden muaf tutularak, kendisinden yardım istenmesi halinde sadece yüz piyade asker göndereceği belirtilmiştir. Aynı şekilde antlaşma tabletinde gelecekte Tarhuntašša krallarının Kurunta'nın soyundan olacağı, bunun aksine hareket eden Hitit krallarının ise tanrıların gazabına uğrayacağı yemin altına alınmıştır. Antlaşmada Kurunta'nın istediği kadın ile evlenebileceği, erkek çocuğu olmasa dahi kız çocuğunun kral olabileceği ayrıca Kurunta'nın neslinden birinin suç işlemesi durumunda ise bunun Hitit Kralı tarafından sorgulanacağı, ancak ülkesinin elinden alınmayacağı belirtilmiştir (Karauğuz 2002: 101-103). Yine bu antlaşmanın son bölümünde antlaşmayı "Tawa şehrinde, prens Nerikkaili, Kargamıš Ülkesi Kralı Ini-Tešup, Šeha Nehri Ülkesi Krahı Mašturi, kralın eniştesi Šaušga-muva, Amurru Ülkesi Kralı Bentešina, ve siralanan diğer isimlerle birlikte ordunun tüm komutanlar, bin yüksek makam sahibi kişi ve tüm kral ailesi huzurunda katip Halwa-ziti'nin

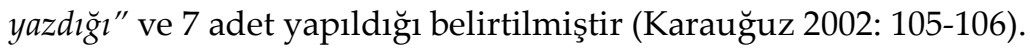

SEFAD, 2018 (40): 267-282 


\section{SONUÇ}

MÖ II. binyılda Anadolu'da Kızılırmak Nehri'nin oluşturduğu çekirdek bölge başta olmak üzere bu bölgede yaşamış ve Eski Yakın Doğu'nun en büyük imparatorluklarından birini kurmuş olan Hititler, bu imparatorluğu 450 yıl boyunca ayakta tutmayı başarmışlardır. Hitit Devleti'nin asıl kurucusunun I. Hattušili (MÖ 1650-1620) olduğu kabul edilmektedir. Hattušili, günümüzde Çorum'a bağlı ve $82 \mathrm{~km}$ uzağında bulunan Boğazköy'deki Hattuşa'yı kendine başkent yapmıştır.

Anadolu'da yaklaşık 450 yıl hüküm süren Hititlerin bu başarısının altında yatan temel nedenlerin başında, hiç şüphesiz zekice yürütülen diplomasi ve idari devlet yapılanmasının önemli olduğu düşünülmektedir. Hitit Krallığı'nın dış politikada yürüttükleri siyasetin temel amacı, uluslararası dengeleri gözeterek mümkün olduğunca düşman ülke sayısını azaltmak olmuştur. Hitit kralları bu siyaseti izlerken bir taraftan, zamanın güçlü krallıklarını (Mısır Krallığı, Asur Krallığı) kendileriyle eşit düzeyde kabul etmişler diğer taraftan da, güçlü ülkeler ile kendi ülkelerinin sınırları arasında tampon bölge oluşturmak amaciyla Mitanni ve Amurru gibi ülkelerle iyi ilişkiler kurmaya özen göstermişlerdir. Hititler bu politikalarını gerçekleştirmek amacıyla merkezden uzak bölgelerin idaresini kolaylaştırmak ve merkezi idarenin yükünü hafifletmek amacıyla vassallık sistemini geliştirmişlerdir. Diğer bir ifadeyle Hititler kendilerine bağladıkları yeni ülkeleri, Büyük Krala bağlı ve güvenilir vassal kral atayarak yönetmişlerdir. Ancak Büyük Kral tarafından atanan bu krallarla vassal statüde antlaşmalar yapılmıştır. Hitit Krallığı'nın çıkarlarının korunduğu ve vassal kralın etkisinin bulunmadığı bu antlaşmalar Hitit kralı için direktif, vassal kral için ise yemin anlamı taşımaktaydı.

Anadolu'da (Hurri-Mitanni, Kizzuwatna, Išuva, Azzi-Hayaša, Arzawa Ülkeleri Krallığı) ve Mezopotamya bölgesinde (Kargamıš, Halep, Ugarit, Amurru, Nuhašše ve Kinza Krallığı) dönem dönem vassal statüyle Hititlere bağlı olan krallıklar vardı. Hitit kralları atadıkları vassal krallar sayesinde bir taraftan Hatti topraklarının güvenliğini sağlamışlar, diğer taraftan da merkezden uzak bu krallıkları daha kolay yönetmişlerdir. Hitit kralları gerektiğinde vassal krala hanedan ailesinden birini eş vererek vassal krallıkla ilişkileri sıcak tutmaya çalışmışlardır. Hitit kralları yaptıkları bu antlaşmalarda vassal krallara kaçaklar, kışkırtıcılar, yalan haber yayanlar, suçlular ve isyancılar hakkında yapacakları işlemler hakkında ortak yükümlülükler getirmişlerdir. Diğer taraftan ise muhtemelen vassal krallığın içinde bulunduğu siyasi ve jeopolitik konumlarını da dikkate alarak farklı yükümlülükler yemin altına alınmıştır. Örneğin Kizzuwatna Ülkesi Kralı Šunaššura ile II. Tuthaliya arasında yapılan antlaşmada, Šunaššura'nın Hurri elçilerini kabul etmemesi ve Mitanni ülkesinin Hatti'ye saldırı durumunda askerlerinin Kizzuwatna topraklarından geçişine izin verilmemesi yemin altına alınmıştır. Aynı şekilde Ugarit Kralı Niqmepa ile II. Muršili arasında yapılan antlaşmayla Niqmepa'ya sadece Büyük Hitit kralını koruması ancak Mısır ya da Hanilgabat kralını korumaması yönünde yükümlülük getirilmiştir. IV. Tuthaliya tarafından Amurru'ya vassal kral yapılan Şauşga-muwa ile yapılan antlaşmada ise diğer antlaşmalardan farklı olarak, Amurrulu tüccarların Asur'a gitmemesi ve Asurlu tüccarların da Amurru'ya girişine izin verilmemesi yemin altına alınmıştır. Bu farklı yaptırımların içeriği özünde incelendiğinde, hepsinin altında yatan önceliğin Hatti topraklarının güvenliği ve çıkarlarının yattığı kolaylıkla anlaşılacaktır.

Diğer taraftan Kargamıš, Halep ve Tarhuntašša gibi ülkelere Hitit hanedan soyundan birinin vassal kral olarak atandığını görmekteyiz. Doğal olarak hanedan soyundan birinin 
kral olarak atanması, Hitit Krallığı için bir güvence gibi gözükmektedir. Ancak Hitit krallarının hanedan soyundan atadıkları bu krallar ile yaptıkları antlaşmalarda daha özverili olduklarını görüyoruz. Bunun altında yatan neden ise antlaşma metinlerine yansıdığı gibi, bu kralların gelecekte Hitit Krallı̆̆ı'nda söz sahibi olmamaları ve çıkabilecek taht kavgalarının önüne geçmek olmuştur. Buna örnek olarak II. Muršili ile kardeşi Kargamıš Kralı Piyaššili arasındaki antlaşmada Piyaššili ve gelecekteki soyunun sürekli Kargamıš vassal kralı olacakları ve Kargamıš krallığının statüsünün ise Hatti Büyük Kralından sonra geleceğinin yemin altına alınmış olması verilebilir. Benzer şekilde III. Hattušili'nin Tarhuntašša'ya kral yaptığ 1 yeğeni Kurunta'dan Šahhan ve Luzzi vergileri ile bazı askeri yükümlülüklerin kaldırılmış olması da buna örnek oluşturmaktadır.

\section{SUMMARY}

The Hittites, who lived in the region formed by the Kizılırmak River in Anatolia in the second Millennium BC, established one of the biggest empires of the Ancient Near Eastern and managed to keep this empire alive for 450 years. Hattušili I (1650-1620) is accepted as the founder of the Hittite Kingdom. Hattusa (Boğazköy), which is $82 \mathrm{~km}$ away from Çorum city center today, had been chosen as the capital by Hattušili.

One of the main reasons behind the success of the Hittites, who ruled for 450 years in Anatolia, is undoubtedly a cleverly conducted diplomacy and administrative state structure. The main purpose of the foreign policy of the Hittite Kingdom was to reduce the number of hostile countries as much as possible by taking into account the international balances. For this policy, the Hittite Kings, on the one hand, accepted the powerful kingdoms of the time (such as Egypt Kingdom and Assyrian Kingdom) at the same level with themselves. On the other hand, they tried to establish good relations with countries such as Mitanni and Amurru to create a buffer zone between the strong countries and the borders of their country. So, they developed the vassal system in order to facilitate the administration of the remote areas and to ease the burden of the central administration. In other words, the Hittites administered the new countries by appointing trustworthy vassal kings who are loyal to the Great King. In the meantime, vassal status treaties were made with these kings. These treaties, in which the interests of the Hittite Kingdom were preserved and the vassal king had no influence, mean a directive for the Hittite king, and an oath for the vassal king.

It is seen that vassal state structure was formed by Šuppiluliuma I and improved by Muršili II. Among the signed 21 vassal treaties, 6 of them were made by Šuppiluliuma I, 6 of them by Muršili II, 3 of them by Hattušili III, 2 each with Muwatalli II and Tuthaliya IV and 1 each with Tuthaliya II and Šuppiluliuma II.

Both in Anatolia (Hurri-Mitanni, Kizzuwatna, Išuva, Azzi-Hayaša, Arzawa Country Kingdoms) and Mesopotamia regions (Kargamıš, Aleppo, Ugarit, Amurru, Nuhašše and Kinza Kingdoms), time to time, there were kingdoms bound to the Hittites with the vassal status. The Hittite kings, on the one hand, ensured the security of the Hatti lands through the vassal kings they appointed; on the other hand, they administered these distant kingdoms more easily. In the treaties, the Hittite kings have brought common obligations to the vassal kings about the actions for the fugitives, provocateurs, criminals and rebels. On the other hand, different obligations were put into force under oath, taking into consideration the political and geopolitical positions of the vassal kingdom. For example, with the treaty between the King of Kizzuwatna Šunaššura and Tuthaliya II, Šunaššura took 
an oath to not accept the Hurri envoy and not let the soldiers pass through the territory of Kizzuwatna in the case of Mitanni country attacking Hatti. Similarly, with the treaty between Ugarit King Niqmepa and Muršili II, Niqmepa obligated to protect only the Great Hittite king, not the Egypt or the Hanilgabat kings. Unlike others, in the treaty with Şauşgamuwa, who was appointed as a vassal king to Amurru by Tuthaliya IV, he took an oath for the Amurru traders not to go to Assyria and not allow the Assyrian traders to enter Amurru. When the content of these different sanctions is examined, it is easily understood that the underlying priority of all of them was the security and interests of the Hatti lands.

On the other hand, we see that Hittite dynasty descendants were appointed as vassal kings to countries such as Kargamıš, Aleppo and Tarhuntašša. Naturally, the appointment of one of the dynasty descendants as the king seems to be a guarantee for the Hittite Kingdom. However, we know that the Hittite Kings were more selfless in their treaties with the kings they had appointed from the dynasty line. As reflected in the treaty texts, the underlying reasons for this were to prevent both these kings from having a say in the future Hittite Kingdom and fights for the throne. As an example, in the treaty between Muršili II and his brother to the King Piyaššili of Kargamıš, it was under oath that Piyaššili and his future generations would be the permanent vassal king of Kargamıš, and the status of the kingdom of Kargamıš would be ranked just after the Great King of Hatti. Similarly, the removal of Šahhan and Luzzi taxes and some military obligations from Kurunta, who is the nephew of Hattušili III appointed as a king to Tarhuntašša by him, is an example. 


\section{KAYNAKÇA}

Akdoğan, Rukiye (2010). “Hitit Antlaşmaları, Devletin Dili”. Aktüel Arkeoloji Dergisi. (13): 94103.

Alemdar, Derya (2006). Kizzuwatna Memleketi İle Hitit Deoleti Arasında Yapılan Antlaşmalar. Yüksek Lisans Tezi. Ankara: Ankara Ü.

Alp, Sedat (2000). Hitit Çağında Anadolu. Çivi Yazll ve Hiyeroglif Yazılı Kaynaklar. İstanbul: TÜBITTAK Popüler Bilim Kitaplarn 140.

Alpman, Adil (1981). “Hurriler". Tarih Araştırmaları Dergisi (25): 283-313.

Ayaz, Sema (2017). Çivi Yazılı Belgelere Göre Hitit Devletine Bağlı Devletlerin Statüsü. Yüksek Lisans Tezi. Ankara: Gazi Ü.

Bahar, Hasan (2013). Eskiçă̆ Uygarlikları. Konya: Kümen Yayınları 53.

Bahar, Hasan (2017). “Türklerden Önce Konya Tarihi”, Konya Araştırmaları Göç ve İskan. ed. Alaattin Aköz- Doğan Yörük. Konya: Palet Yayınları. 29-44.

Bahar, Hasan-Karauğuz, Güngör vd. (1996). Eskiçă̆ Konya Araştırmaları 1. Phrygia Paroreus Bölgesi: Anıtlar, Yerleşmeler ve Küçük Buluntular. İstanbul: Fs Yayınları.

Balkan, Kemal (1957). Mama Kralı Anum-Hirbi'nin Kaniş Kralı Warşama'ya Gönderdiği Mektup. Ankara: Türk Tarih Kurumu Basımevi.

Beckman, Gary (1996). Hittite Diplomatic Texts. ed. Harry, A-Hoffner, Jr. Atlanta, Georgia: Scholars Press.

Bryce, Trevor (2003). Letters of the Great Kings of the Ancient Near East. The Royal Correspondence of the Late Bronze Age. London-New York.

Bryce, Trevor (2015). The Kingdom of The Hittites. New Edition. Oxford.

Christiansen, Birgit., Devecchi, Elena (2013). "Die Hethitischen Vassallenverträge und die Biblische Bundeskonzeption". Biblische Notizen. Nr. 156, 65-85.

D'Alfonso, Lorenzo (2007). "The Treaty Between Talmi-Teššup king of Karkemiš and Šuppiluliyama Great king of Hatti“, Tabularia Hethaeorum: Hethitologische Beiträge. Silvin Košak zum 65. Geburtstag, ed. Detlev Groddek- Marina Zorman. Wiesbaden. Harrassowitz Verlag. 202-220.

De Martino, Stefano (2003). Hititler. Ankara: Dost Kitabevi Yayınları.

Demirel, Serkan (2017). “A Contribution to Localization of Azzi-Hayaša Mentioned in Hittite Cuneiform Texts". Archivum Anatolicum (ArAn) (1): 97-110.

Goetze, Albrecht (1962). "Cilicians". JCS (16): 48-58.

Günbattı, Cahit (2012). Kültepe-Kaniş. Anadolu'da İlk Yazı, İlk Belgeler. Kayseri: Kültür Yayınları.

Karauğuz, Güngör (2002). Boğazköy ve Ugarit Çivi Yazılı Belgelere Göre Hitit Devletinin Siyasi Antlaşma Metinleri. Konya: Çizgi Kitapevi Yayınları 48.

Kitchen, Kenneth. A and Lawrence, Paul. J. N (2012). Treaty, Law and Covenant in the Ancient Near East. Wiesbaden. Harrassowitz Verlag.

Küçükbezci, Hatice Gül (2010). M. Ö. II. binyılda Yılın İlk Çeyreğinde (Assur Ticaret Kolonileri Çă̆g'nda) Orta Anadolu'nun Sosyoekonomik Yapısı. Doktora Tezi. Konya: Selçuk Ü.

Macqueen, J. G (2015). Hititler ve Hitit Çağında Anadolu. çev. Esra Davutoğlu. Ankara. Arkadaş Yayınevi.

Monte, Giuseppe F. Del and Tischler, Johann (1978). Die Orts- und Gewässernamen der Hethitischen Texte. Réportoire Géographique des textes Cunéiformes VI. Wiesbaden.

Otten, Heinrich (1988). Die Bronzetafel aus Bogazkoy. Ein Staatsvertrag Tuthalijas IV. Studien zu den Bogazkoy-Texten, Beiheft 1. Wiesbaden. Harrassowitz Verlag.

SEFAD, 2018 (40): 267-282 
Özgüç, Tahsin (1986). Kültepe-Kaniş II. Eski Yakındoğu'nun Ticaret Merkezinde Yeni Araştırmalar. Ankara. Türk Tarih Kurumu Yayınları.

Peker, Hasan (2013). "Hitit Devleti'nin Uluslararası İlişkileri ve Politik Enstrümanları: Savaş ve Diplomasi". Hititler. Bir Anadolu İmparatorluğu ed. Meltem Doğan Alparslan- Metin Alparslan. İstanbul: Yapı Kredi Yayınları 4017. 64-78.

Pelvanoğlu, Tolga (2017). MÖ İkinci Binyılda Kizzuwatna'nın Tarihi ve Tarihi Coğrafyası. Yüksek Lisans Tezi. İstanbul: İstanbul Ü.

Sir Gavaz, Özlem (2008). "Hitit İmparatorluk Devri Krallarından I. Şuppiluliuma Döneminde Anadolu". Hitit Üniversitesi Sosyal Bilimler Enstitüsü Dergisi (1): 21-39.

Sir Gavaz, Özlem (2012). "MÖ 14. Yüzyılda Hitit Vassali Ugarit, Mısır ve Doğu Akdeniz". Arkeoloji ve Sanat (140): 25-34.

Sommer, Ferdinand (1947). Hethiter und Hethitisch. Stuttgart.

Taş, İlknur (2008). Hitit Kralı IV. Tuthaliya. Asur Devleti'ne ve Suriye'deki Vassal Krallklara Yönelik Politikası. İstanbul: Arkeoloji ve Sanat Yayınları.

Taş, İlknur (2012a). "Hitit Kralı IV. Tuthaliya'nın Suriye Politikası". 38. ICANAS Uluslararası Asya ve Kuzey Afrika Çalışmaları Kongresi Bildiriler (haz. Zeki Dilek, Mustafa Akbulut vd.) 10-15. 09. 2007. Ankara: Atatürk Kültür, Dil ve Tarih Yüksek Kurumu Yayınları. VI. Cilt, 3029-3038.

Taş, İlknur (2012b). “MÖ 13. Yüzyılda Hitit Kralı IV. Tuthaliya'nın Uygulamaya Koyduğu Ticari Ambargo". 38. ICANAS Uluslararası Asya ve Kuzey Afrika Çalışmaları Kongresi Bildiriler. (haz. Zeki Dilek, Mustafa Akbulut vd.) 10-15. 09. 2007. Ankara: Atatürk Kültür, Dil ve Tarih Yüksek Kurumu Yayınları. 2012. VI. Cilt, 3015-3027.

Ünal, Ahmet (2005). Hititler Devrinde Anadolu III. İstanbul: Arkeoloji ve Sanat Yayınları.

Ünal, Ahmet (2006). “Eski Çağlarda Çukurova'nın Tarihi Coğrafyası ve Kizzuwatna (Adana) Krallı̆̆ı'nın Siyasi Tarihi”. Çü Sosyal Bilimler Enstitüsü Dergisi (3): 15-44.

Yiğit, Turgut (2004). "Hitit Krallığı'nda Yönetim Sistemi Üzerine Bir Not". Ankara Üniversitesi Dil ve Tarih-Coğrafya Fakültesi Tarih Bölümü Tarih Araştırmaları Dergisi (35): 219-226. 